\title{
ANALISIS TINGKAT PENYIMPANAN SENYAWA KARBON (C-Stock) PADA VEGETASI HUTAN MANGROVE BERDASARKAN PERBEDAAN SUBTRAT DI PULAU SAPARUA KABUPATEN MALUKU TENGAH
}

\author{
Patriks Sitaniapessy ${ }^{1}$ P. M. Papilaya ${ }^{2}$ \\ ${ }^{1}$ Alumni Program Studi Pendidikan Biologi \\ ${ }^{2}$ Dosen Program Studi Pendidikan Biologi \\ E-mail: joyfullpamela@yahoo.co.id
}

\begin{abstract}
Background: Analysis of the level of storage of Carbon compounds (C-Stock) on mangrove forest vegetation based on differences in substrate on Saparua Island, Central Maluku Regency. This study aims to determine the amount of carbon content and the difference in carbon content stored in mangrove forests.

Method: This study used a survey method through direct observation in the field and analysis of sample weight in the laboratory. The data obtained were analyzed using the biomass estimation formula and carbon content and statistical equation to determine the difference in carbon content at each station.

Results: From the results of the study obtained total carbon in station I was 3.498351 tons / ha, station II was 0.180750 tons / ha and station III was 16.727136 tons / ha.

Conclusion: With the difference of each station based on the BNT Test with a confidence level of $99 \%$ showing the value of the difference of 20.58 , while the BNT test of the confidence level of $95 \%$ shows the difference in value of 13.59 .
\end{abstract}

Keywords: Vegetation of mangrove forests and carbon content.

\begin{abstract}
Abstrak
Latar Belakang: Analisis tingkat penyimpanan senyawa Karbon (C-Stock) pada vegetasi hutan mangrove berdasarkan perbedaan subtrat di Pulau Saparua Kabupaten Maluku Tengah. Penelitian ini bertujuan untuk mengetahui besar kandungan karbon dan perbedaan kandungan karbon yang tersimpan pada hutan mangrove.

Metode: Penelitian ini menggunakan metode survey melalui pengamatan langsung di lapangan dan analisis berat sampel di laboratorium. Data yang diperoleh dianalisis dengan menggunakan rumus pendugaan biomassa dan kandungan karbon dan persamaan statistik untuk mengetahui perbedaan kandungan karbon pada tiap stasiun.

Hasil: Dari hasil penelitian diperoleh total karbon pada stasiun I sebesar 3,498351 ton/ha, stasiun II sebesar 0,180750 ton/ha dan stasiun III sebesar 16,727136 ton/ha.

Kesimpulan: Dengan perbedaan setiap stasiun berdasarkan Uji BNT dengan tingkat kepercayaan 99\% menunnjukkan nilai perbedaan sebesar 20,58, sedangkan uji BNT tingkat kepercayaan 95\% menunjukkan nilai perbedaan sebesar 13,59.
\end{abstract}

Kata kunci: Vegetasi hutan mangrove dan kandungan karbon. 


\section{PENDAHULUAN}

Hutan mangrove ditemukan di daerah perairan payau di antara daratan dan laut di daerah tropis dan subtropis. Hutan mangrove adalah salah satu vegetasi hutan yang hanya dapat tumbuh dan berkembangbiak di daerah tropis seperti Indonesia, terutama di Kalimantan , Sumatra, Irian jaya, Kepulauan Aru,dan sedikit di Sulawesi bagian selatan dan Jawa bagian utara (Bengen, 2000). Manggrove adalah sebutan umum yang digunakan untuk menggambarkan suatu varietas komunitas pantai tropik yang didominasi oleh beberapa spesies pohon-pohon yang khas atau semak-semak yang mempunyai kemampuan untuk tumbuh dalam perairan asing (Nybakken 1992).

Secara biologis hutan mangrove memiliki banyak fungsi antara lain sebagai daerah asuhan (nursery ground) bagi biota yang hidup pada ekosistem mangrove, fungsi yang lain adalah sebagai daerah mencari makan (fedding ground) karena mangrove merupakan produsen primer yang mampu menghasilkan sejumlah besar detritus dari daun dan pohon mangrove dimana dari sana tersedia banyak makanan bagi biota-biota yang mencari makanan pada daerah mangrove tersebut, fungsi yang ketiga adalah sebagai daerah pemijahan (spawning ground) bagi ikanikan tertentu agar terlindungi dari predator sekaligus mencari lingkungan yang optimal untuk memisah dan membesarkan anaknya, selain itu merupakan pemasok larva udang, ikan dan biota lainya (Tomlinson, 1994; Hogarth,2007).

Mangrove juga banyak memberikan fungsi ekologis di antaranya sebagai pelindung garis pantai, menjaga intrusi air laut, sebagai habitat (tempat tinggal) berbagai organisme laut dan juga terestrial. Vegetasi hutan mangrove mamemiliki pengaruh dalam mengurangi jumlah karbon di udara dengan cara menyerap $\mathrm{CO}_{2}$ melalui proses fotosintesis, atau dikenal sebagai proses sequestration. Karbon yang diserap oleh vegetasi mangrove akan disimpan dalam bentuk biomassa pohon. Besarnya biomassa pohon tersebut akan mampengaruhi niali kandungan karbon dari pohon tersebut. Menurut Boulion et al. (2003), hutan mangrove memiliki produktivitas yang cukup tinggi dan memiliki kemampuan untuk menyimpan karbon organik yang sangat penting. Menurut Ong (1993), secara global dapat di perkirakan hutan mangrove dapat menyerap $\mathrm{CO}_{2}$ dari atmosfer sebesar 25,5 juta ton/tahun. Potensi mangrove sebagai penyerap karbon sangat besar mengingat luas mangrove yang ada di kawasan hutan mangrove Indonesia merupakan hutan mangrove terluas di dunia.

Proses penimbunan karbon dalam tubuh tumbuhan dinamakan proses sekuestrasi (C-sequestration), proses sekuestrasi merupakan kemampuan pohon untuk dapat menyerap karbon di udara. Dengan demikian mengukur jumlah karbon yang disimpan dalam tubuh tanaman hidup (Biomassa) pada suatau lahan dapat menggambarkan $\mathrm{CO}_{2}$ di atmosfer yang diserap oleh tanaman, sedangkan pengukuran karbon yang masih tersimpan dalam bagian tumbuhan yang telah mati (nekromassa) secara tidak langsung menggambarkan $\mathrm{CO}_{2}$ yang tidak dilepaskan ke udara melalui pembakaran.

Penelitian ini dilaksanakan dipulau Saparua dengan mengambil 3 lokasidaerah penelitian yaitu pantai Desa Tiouw, pantai Desa Haria dan pantai daerah tambak Desa Haria, pembagian daerah penelitian diasari oleh perbedaan subtract atau dasar perairan yaitu daerah Tiouw memiliki subtrat pasir berlumpur, pantai Desa Haria memiliki subtract pasir berkarang dan daerah lokasi penelitian tambak Desa Haria memiliki subtract berkarang.

\section{MATERI DAN METODE}

Jenis penelitian ini adalah penelitian komparatif dengan menggunakan metode perhitungan biomassa untuk mengetahui perbedaan tingkat penyerapan senyawa karbon ( $C$ - stock) pada vegetasi hutan mangrove kecamatan saparua. Penelitian ini dilaksanakan di Pulau saparua dengan 3 lokasi yang berbeda yaitu di kawasan Desa Tiouw, kawasan Haria tambak dan kawasan Haria kampung. Proses pengambilan sampel menggunakan metode penetuan titik (Quik Park Center).

Sampel yang di temukan pada lokasi penelitian kemudian di analisis berat basa dan berat keringnya pada laboratorium biologi dasar dan selanjutnya di analisis 
dengan menggunakan rumus BEF (Biomassa Expension Faktor).

$$
\mathrm{Bi}=\frac{\mathrm{Wi}}{\mathrm{V}}
$$

$\mathrm{Bi} \quad=\mathrm{BEF} \mathrm{Ki}$ (Akar, Batang, daun).

$\mathrm{Wi}=$ Berat kering komponen $\mathrm{ke} \mathrm{I}(\mathrm{Kg})$

$\mathrm{V}=$ Volume Batang $\left(\mathrm{m}^{3}\right)$

Perhitungan kandungan karbon dengan persamaan karbon organic. $\mathrm{Cb}=\mathrm{B} \times \% \mathrm{C}$ organic. Hasil karbon dianalisis dengan menggunakan rumus statistic Anova satu jalur dan uji BNT $1 \%$ dan $5 \%$ untuk mengetahui apakah terdapat perbedaan kandungan karbon terhadapa ketiga lokasi penelitian.

\section{HASIL DAN PEMBAHASAN}

Hasil pengukuran faktor lingkungan pada masing-masing lokasi dapat dilihat pada tabel berikut.

Tabel 1. Parameter Lingkungan

\begin{tabular}{llll}
\hline Lokasi & Suhu & Salinitas & $\mathbf{p H}$ \\
\hline Tiouw & $33-34^{\circ} \mathrm{C}$ & $30 \mathrm{ppt}$ & 6 \\
\hline Haria Tambak & $31-33^{\circ} \mathrm{C}$ & $29 \mathrm{ppt}$ & 5 \\
\hline Haria Kampung & $35-36^{\circ} \mathrm{C}$ & $31 \mathrm{ppt}$ & 7 \\
\hline
\end{tabular}

Berdasarkan tabel di atas terlihat secara jelas bahwa kondisi parameter lingkungan pada ketiga lokasi penelitian mempunyai perbedaan yang tidak terlalu jauh, ini dapat dibuktikan pada tabel pengukuran parameter lingkungan di atas di mana keadaan suhu tertinggi berada pada lokasi Haria Kampung $\left(35-36^{\circ} \mathrm{C}\right)$ dan suhu terendah berada pada lokasi Haria tambak $\left(31-33^{\circ} \mathrm{C}\right)$. Untuk pengukuran salinitas tergambar bahwa kondisi salinitas tertinggi berada pada lokasi Haria kampung (31ppt) dan terendah berada pada lokasi Haria tambak (29ppt). Untuk pengukuran $\mathrm{pH}$ tergambar bahwa kondisi $\mathrm{pH}$ tertinggi berada pada lokasi Haria kampong dan $\mathrm{pH}$ terendah berada pada Haria tambak.
Tabel 2. Total Biomassa Keseluruhan Untuk Stasiun I (Desa Tiouw).

\begin{tabular}{cll}
\hline No & \multicolumn{1}{c}{ Nama Spsies } & \multicolumn{1}{c}{ Total } \\
\hline 1 & $\begin{array}{l}\text { Avicennia } \\
\text { eucalyptifolia }\end{array}$ & $1,876 \mathrm{~g}$ \\
\hline 2 & Avicennia lanata & $0,0492 \mathrm{~g}$ \\
\hline 3 & Bruguiera sexangula & $1,287 \mathrm{~g}$ \\
\hline 4 & Ceriops tagal & $4,215 \mathrm{~g}$ \\
\hline 5 & Sonneratia alba & $0,0161 \mathrm{~g}$ \\
\hline & Total & $\mathbf{7 , 4 4 3 3} \mathbf{~ g}$ \\
\hline
\end{tabular}
Tabel 3. Total Biomassa Keseluruhan Untuk Stasiun II (Haria Tambak).

\begin{tabular}{cll}
\hline No & \multicolumn{1}{c}{ Nama Spsies } & \multicolumn{1}{c}{ Total } \\
\hline 1 & Bruguiera sexangula & $0,06388 \mathrm{~g}$ \\
\hline 2 & Rhizophora apiculata & $0,086744 \mathrm{~g}$ \\
\hline 3 & Rhizophora mocronata & $0,04856 \mathrm{~g}$ \\
\hline 4 & Bruguiera hainessi & $0,02881 \mathrm{~g}$ \\
\hline 5 & Aegiceras floridum $R$ & $0,0526 \mathrm{~g}$ \\
\hline 6 & Aegiceras curniculatum L & $0,00601 \mathrm{~g}$ \\
\hline 7 & Bruguiera palviflora & $0,04113 \mathrm{~g}$ \\
\hline 8 & Bruguiera exaristafa & $0,00766 \mathrm{~g}$ \\
\hline 9 & Sonertia alba & $0,0492 \mathrm{~g}$ \\
\hline & Total & $\mathbf{0 , 3 8 4 5 9 4 \mathbf { ~ g }}$ \\
\hline
\end{tabular}

Tabel 4. Total Biomassa Mangrove Keseluruhan Untuk Stasiun III (Haria Kampung).

\begin{tabular}{cll}
\hline No & Nama Spesies & Total \\
\hline 1 & Rhizphora stylosa & $0,04506 \mathrm{~g}$ \\
\hline 2 & Bruguiera gymnorhiza & $0,0548 \mathrm{~g}$ \\
\hline 3 & Amyena grafis dans & $0,03485 \mathrm{~g}$ \\
\hline 4 & Ceriops tagal & $0,14471 \mathrm{~g}$ \\
\hline 5 & Phempis adicula & $0,19315 \mathrm{~g}$ \\
\hline 6 & Phempis adicula bonsai & $0,06482 \mathrm{~g}$ \\
\hline 7 & Lumnitzera racemosa & $0,17948 \mathrm{~g}$ \\
\hline 8 & Ceriops decandra & $34,31718 \mathrm{~g}$ \\
\hline & Total & $\mathbf{3 5 , 5 8 9 6 5}$ \\
\hline
\end{tabular}

Sebaran masinng-masing biomassa bagian tanaman akan mempengaruhi alokasi biomassa masing-masing bagian tanaman. Alokasi masing-masing bagian tanaman berbeda-beda (Kirby and Potvin, 2007; Nath et al, 2009; Navar, 2009). Berdasarkan Hasil penelitian diatas tergambar bahwa akomulasi biomassa terbesar berada pada stasiun penelitian III (Haria Kampung) 35,58965 g. Perbedaan 
jumlah biomassa antara ketiga stasiun penelitian tersebut disebabkan oleh beberapa factor diantaranya kondisi tegakan yang berbedah sepertih tinggi pohon, diameter pohon dan kerapatan vegetasi serta umur pohon.Walpone (1993). mengungkapkan bahwa jumlah biomassa berhubungan erat dengan dimensi (tinggi dan diameter) pohon. Selain itu, akumulasi biomassa suatu tanaman dipengaruhi oleh umur, ketersediaan hara pada subtrat, tanah, dan iklim setempat (Brown, 1997).

Tabel 5. Total Karbon Tiap Stasiun

\begin{tabular}{lcc}
\hline Lokasi Penelitian & Total Biomassa & Total Karbon Tersimpan \\
\hline Stasiun I & $7,4433 \mathrm{~g}$ & 3,498351 ton/ha \\
\hline X2 & $\mathbf{5 5 , 4 0 2 7 1 9} \mathbf{~ g}$ & $\mathbf{1 2 , 2 3 8 4 5 0}$ ton $/ \mathrm{ha}$ \\
\hline Stasiun II & $0,384594 \mathrm{~g}$ & 0,180750 ton/ha \\
\hline X2 & $\mathbf{0 , 1 4 7 9 1 2 1} \mathbf{~ g}$ & $\mathbf{0 , 0 3 2 6 7 0 6}$ ton $/ \mathrm{ha}$ \\
\hline Stasiun III & $35,58965 \mathrm{~g}$ & 16,727136 ton/ha \\
\hline X2 & $\mathbf{1 , 2 6 6 . 6 2 3 9} \mathbf{g}$ & $\mathbf{2 7 9 , 7 9 7 0}$ ton/ha \\
\hline Total & $43,417544 \mathrm{~g}$ & 20,406237 ton/ha \\
\hline Total X2 & $\mathbf{1 , 8 8 5 . 0 8 3 1 2 5} \mathbf{~ g}$ & $\mathbf{4 1 6 , 4 1 5 0 8 6}$ ton/ha \\
\hline
\end{tabular}

Jumlah biomassa yang tersimpan dalam tegakan pohon dapat digunakan untuk mengetahuai jumlah karbon yang tersimpan pada tegakan pohon, karena $46 \%$ biomassa adalah berbentuk karbon (Brown.S. dan Lugo, A.E. 1984). Berdasarkan teori di atas maka hasil perhitungan karbon pada vegetasi hutan mangrove Desa Tiouw (stasiun I) sebesar 3,498351 ton/ha, kawasan tambak Desa Haria sebesar 0,180750 ton/ha (Stasiun II) dan kawasan haria kampong sebesar 16,727136 ton/ha (stasiun III). Besar cadangan karbon yang di hasilkan tergantung pada biomassa tanaman. Stasiun penelitian III memiliki kandungan cadangan karbon yang lebih banyak dari pada pada Stasiun penlitian I dan II di mana Stasiun penelitian III didonominasi oleh pohon mangrove yang diameter pohonya dari $30 \mathrm{~cm}$, selain mangrove pada satisiun III juga memiliki umur yang lebih dari mangrove pada stasiun I dan stasiun II ( pada spesies Ceriops decandra).

Selain itu penyerapan karbon oleh tanaman juga di pengaruhi oleh luas penampang daunnya, hubungan ini sangat erat dengan proses fotosintesis, secara morfologi tampak nyata bahwa spesiesspesies mangrove yang di temukan pada stasiun III memiliki luas daun yang besar dari mangrove pada stasiun I dan II. Dari hasil penelitian maka bukan tidak mungkin bahwa keberadaan subtrat tumbuh (dasar perairan) pada mangrove juga mempengaruhi total kandungan karbon yang dihasilkan, karna pada prisipnya karbon yang diserap kedalam tubuh tumbuhan bukan semata-mata hanya diserap dengan stomata saja tapi juga dari subtrat tumbuh mangrove, hal ini dapat terlihat lewat hasil penelitian diatas bahwa kandungan karbon terbesar berada pada stasiun penelitian III (kawasan Haria Kampung) 16,727136 ton/ha. Dengan memiliki subtract tumbuh mangrove pasir berkarang. Dari hasil uji statistik yang dilakukan terlihat besar perbedaan untuk uji BNT $1 \%$ adalah 20,58 dan uji BNT 5\% adalah 13,59. Dari hasil ini terlihat perbedaan yang cukup signifikan karna nilai $F_{\text {hit }}>F_{\text {tabel. }}$.

\section{KESIMPULAN}

Penelitian ini dapat disimpulkan bahwa 1) Akomulasi biomassa yang di hasilkan dari Stasiun penlitian III (kawasan Haria kampung) 35,58965g lebih besar jika di bandingkan dengan stasiun penelitian I (Desa Tiouw) 7,4433g dan stasiun II (kawasan tambak Desa Haria) 0,384594g, dengan total karbon keseluruhan untuk semua stasiun penelitian adalah 20,406237 ton/ha; 2) Berdasarkan hasil hitung anova dan BNT dapat terlihat perbedaan terhadap kandungan karbon dari ketiga stasiun Uji BNT $1 \%$ memperoleh hasil perbedaan 
sebesar 20,58, sedangkan uji BNT 5\% memperoleh perbedaan sebesar 13,59.

\section{DAFTAR PUSTAKA}

Bengen, D.G. 2000. Sinopsis Ekosistem dan Sumberdaya Alam Pesisir. Pusat Kajian Sumberdaya Pesisir dan Lautan. Institut Pertanian Bogor. Bogor, Indonesia

Brown, S. and Lugo, A.E. 1984. Biomass of Tropical Forest: A New Estimate Based on Forest Volume. Science, 223: 12901293.

Brown. S. 1997. Estumating Biomass and Biomass Change of Tropical Forest. Forestry Paper 134. USA: FAO.

Bouillon, S., Moens, T., Overmeer, I., Koedam, \& Dehairs, F., 2003. Resource utilization patterns of epifauna from mangrove forests with contrasting inputs of local versus imported organic matter. Mar. Ecol. Prog. Ser. 278, 7788.

Hogarth, P. J. 2007. The Biology of Mangroves and Sea grasses. New York: Oxford University Press Inc.
Kirby, K. R., \& Potvin, C. (2007). Variation in carbon storage among tree species: Implications for the management of a small-scale carbon sink project. Forest Ecology and Management, 246, 208221.

Nath, A. J., Das, G., \& Das, A. K. (2009). Above ground standing biomass and carbon storage in village bam- boos in North East India. Biomass and Bioenergy, 33, 1188-1196.

Navar, J. (2009). Allometric equation for tree species and carbon stock for forest of northwest Mexico. Forest Ecology and Management, 257, 427 - 434.

Nyabakken, J. W, 1992. Biologi Laut Suatu Pendekatan Ekologis. Jakarta: Gramedia

Ong, J.E. 1993. Mangroves - a Carbon Source and Sink. Chemosphere, 27: 1097-1107.

Tomlinson, P. B. 1994. The Botany of Mangroves. Cambridge University Press.

Walpole, E.R. 1993. Pengantar Statistika (ed ke-3). Gramedia. Jakarta. 